\section{Airborne Severe Acute Respiratory Syndrome Coronavirus Concentrations in a Negative-Pressure Isolation Room}

\author{
Ying-Huang Tsai, MD; Gwo-Hwa Wan, PhD; \\ Yao-Kuang Wu, MD; Kuo-Chien Tsao, MSc
}

This study used a sensitive polymerase chain reaction method coupled with filter sampling to detect the presence of airborne severe acute respiratory syndrome (SARS) coronavirus in an isolation patient room with a patient with severe acute respiratory syndrome receiving mechanical ventilatory support. Polymerase chain reaction results were negative for SARS coronavirus in room air both before and after patient extubation.

Infect Control Hosp Epidemiol 2006; 27:523-525

Severe acute respiratory syndrome (SARS) is a respiratory infectious disease that has been reported in Asia, North America, and Europe. ${ }^{1}$ So far 8,096 probable SARS cases and 774 deaths have been reported, giving a worldwide case fatality rate of $9.6 \%{ }^{2}$ Infectious agents are carried in airborne droplets produced by aerosolization that can occur from sneezing, coughing, and talking. ${ }^{3}$ Most droplets are $4-8 \mu \mathrm{m}$ in diameter, by microscopic measurement. ${ }^{4}$ Aerosolized SARS coronavirus $(\mathrm{CoV})$ droplets range in size from 0.1 to $0.2 \mu \mathrm{m}^{1,5}$ and survive in the ambient environment for a couple of days. ${ }^{6}$

The World Health Organization has indicated that air travelers seated within 2 rows of an infected person could be in danger of contracting SARS-CoV. ${ }^{7}$ Attack rates for hospital workers are associated with the number of SARS patients admitted to the individual hospitals. ${ }^{8}$ Preventive measures, such as wearing N95 masks and hand washing, are effective for avoiding contact with the respiratory secretions of SARS patients. ${ }^{9}$ Flow balancing of the air distribution system in hospital wards should be performed once a year to decrease nosocomial transmission. ${ }^{10}$

Until recently, few studies had sampled the virus-containing aerosols generated during expulsions from the patient's respiratory tract. Polymerase chain reaction (PCR) analysis amplifies nucleic acids exponentially and is particularly sensitive to the detection of infectious agents. ${ }^{11-14}$ We therefore specifically evaluated airborne SARS-CoV DNA concentrations in a negative-pressure isolation room that housed a patient with SARS who was receiving mechanical ventilatory support. We also evaluated the filtration efficiency of the highefficiency particulate air (HEPA) filters connected to the exhaled breathing circuit of the mechanical ventilator.

\section{METHODS}

Patient. A female patient with SARS who had throat and nasopharynx samples that tested positive by PCR for SARS$\mathrm{CoV}$ on May 12, 2003, was housed in a negative-pressure room in the Chang Gung Memorial Hospital (Taiwan, Republic of China) from May 2 to May 13, 2003, and received mechanical ventilatory assistance from May 2 to May 10. A $0.023-\mu \mathrm{m}$ filter was attached to the exhalation circuit.

Air sampling. After informed consent was obtained from the patient through interviews, air samples were collected from the isolated patient room from May 3 to May 13, 2003. The air sampler and filter cassette were placed approximately $1 \mathrm{~m}$ from the patient's bed. The sampling height was 1.2-1.5 $\mathrm{m}$ above the floor, approximately in the human breathing zone. The indoor air was filtered through a filter cassette with a $1-\mu \mathrm{m}$ polytetrafluoroethylene (PTFE) filter at an airflow rate of $4.5 \mathrm{~L}$ /minute for 8 hours. After air sampling, filters were immediately stored at $-70^{\circ} \mathrm{C}$.

Aerosol generation. To evaluate the removal efficiency for airborne SARS-CoV of both the 0.023- $\mu \mathrm{m}$ and $0.3-\mu \mathrm{m} \mathrm{HEPA}$ filters connected to the breathing circuit, SARS-CoV virucidal sprays were generated using a small-volume nebulizer. ${ }^{14}$ This nebulized solution consisted of diluted SARS-CoV and phosphate-buffered saline, and the median tissue culture infecting dose of SARS-CoV was 100 . Various filters, including $0.2-\mu \mathrm{m}$ PTFE filters and $0.2-\mu \mathrm{m}$ polycarbonate (PC) filters, were used for collection of aerosolized SARS-CoV at a flow rate of 4.5 $\mathrm{L} /$ minute for 20 minutes.

Filter analysis. Prepared 1,120- $\mu \mathrm{L}$ aliquots of AVL buffer containing carrier RNA (Qiagen QIAamp Viral RNA Mini Kit) and $280 \mu \mathrm{L}$ of phosphate-buffered saline were pipetted into a $60-\mathrm{mm}$ Petri dish. These Petri dishes were placed on a shaker, and the filters were stripped for 20 minutes at room temperature. The stripping solution was pipetted into a 15$\mathrm{mL}$ sterile microcentrifuge tube, and $1,120 \mu \mathrm{L}$ of $99 \%$ alcohol was then added to stop all reactions. To extract the RNA from the filter samples, we used the Qiagen QIAamp Viral RNA Mini Kit and followed the manufacturer's protocol.

Real-time reverse-transcriptase PCR assay. After extraction, the viral RNA was quantitatively measured using the real-time reverse-transcriptase (RT) PCR method, according to the protocol specified by Taiwan's Center for Disease Control and Prevention. ${ }^{15}$ The assay included transcription reaction at $48^{\circ} \mathrm{C}$ for 30 minutes; Taq polymerase activation at $95^{\circ} \mathrm{C}$ for 10 minutes; and PCR reaction, which consisted of denaturation at $95^{\circ} \mathrm{C}$ for 15 seconds and primer annealing extension at $60^{\circ} \mathrm{C}$ for 1 minute for 40 replication cycles.

\section{RESULTS}

Eight samples $(2,160 \mathrm{~L}$ of air for a period of 8 hours in each sample) were obtained from the patient's room on May 310,2003 (while the patient was receiving ventilatory assistance), and 3 were obtained on May 11-13, 2003 (after extubation); 1 sample was obtained in a negative-pressure room with a non-SARS patient, and 3 unexposed filters were tested. 
TABLE. Removal Efficiency of 2 Types of High-Efficiency Particulate Air (HEPA) Filters for Aerosolized Severe Acute Respiratory Syndrome Coronavirus

Proportion (\%) of samples with positive PCR results, by type of filter

Sampling method $0.2-\mu \mathrm{m}$ PTFE filter $0.2-\mu \mathrm{m}$ PC filter

Aerosols passing through a $0.023-\mu \mathrm{m}$ HEPA filter Aerosols passing through a $0.3-\mu \mathrm{m}$ HEPA filter $0 / 3(0)$ $0 / 3(0)$

NOTE. $\mathrm{PC}=$ polycarbonate; $\mathrm{PCR}=$ polymerase chain reaction; $\mathrm{PTFE}=$ polytetrafluoroethylene.

All samples exhibited negative SARS-CoV PCR results.

To evaluate the removal efficiency of the $0.023-\mu \mathrm{m}$ HEPA filters connected to the breathing circuit, aerosolized SARS$\mathrm{CoV}$ samples were generated and collected using $0.2-\mu \mathrm{m}$ PTFE filters or $0.2-\mu \mathrm{m}$ PC filters after passage through a $0.023-\mu \mathrm{m}$ HEPA filter. Positive PCR results were obtained for none of these samples from the different sampling filters (PTFE filter and PC filter) (Table). However, although aerosols containing SARS-CoV do pass through a $0.3-\mu \mathrm{m}$ HEPA filter, $100 \%$ of samples from both the $0.2-\mu \mathrm{m}$ PTFE filters and $0.2-\mu \mathrm{m}$ PC filters yielded positive PCR results. The control samples from the environment yielded negative PCR results for SARS-CoV DNA products.

\section{DISCUSSION}

Indoor environments in healthcare settings have various risk factors for infections, especially bioaerosol contamination. To date, few studies have addressed the characteristics of airborne SARS-CoV in healthcare settings. ${ }^{14}$ Previous studies have collected aerosolized rhinovirus samples on PTFE filters with a $2-\mu \mathrm{m}$ pore size at a rate of $8.5 \mathrm{~L} /$ minute for 10 minutes and analyzed with a seminested RT-PCR assay. ${ }^{13}$ In our previous studies, airborne SARS-CoV samples were collected on a 1$\mu \mathrm{m}$ PTFE filter at $4.5 \mathrm{~L} /$ minute for 8 hours and analyzed by real-time RT-PCR assay. ${ }^{14}$ Also, we found that different filters (1- $\mu \mathrm{m}$ and $0.2-\mu \mathrm{m}$ PTFE filters and a $0.2-\mu \mathrm{m}$ PC filter) operated at flow rate of $4.5 \mathrm{~L} / \mathrm{min}$ for 20 minutes yielded $100 \%$ positive results for SARS-CoV PCR.

We tried to collect airborne SARS-CoV samples using 1$\mu \mathrm{m}$ PTFE filters in the our investigation. The results produced no positive PCR results in the air of the negative pressure isolation patient room with an intubated patient. A possible reason for this finding is the use of a $0.023-\mu \mathrm{m}$ HEPA filter connected to the breathing circuit. The removal efficiency of HEPA filters with a $0.023-\mu \mathrm{m}$ or $0.3-\mu \mathrm{m}$ pore size was evaluated in this study. We found that HEPA filters with a pore size of $0.023 \mu \mathrm{m}$ could remove $100 \%$ of aerosolized SARS$\mathrm{CoV}$. We demonstrated that HEPA filtration in the ventilator circuit might reduce the concentration of virus in ambient air surrounding an intubated patient to undetectable levels.

Moreover, the room air was not found to contain SARS$\mathrm{CoV}$ DNA products after the patient was extubated. A possible explanation for this finding is the combined effect of clinical therapy for the patient and lower SARS-CoV concentrations in the room air. Because we studied only one patient receiving mechanical ventilatory assistance in our study, and we collected no samples without HEPA filtration in the ventilator circuit, we will consider attempting to reproduce our findings if more patients with SARS become available for study.

We sought to detect SARS-CoV in a negative-pressure isolation room housing a SARS patient receiving mechanical ventilatory support by analysis with a real-time RT-PCR amplification method. Our study found that SARS-CoV was detected by the real-time RT-PCR and that aerosols containing SARS-CoV did pass through a 0.3- $\mu \mathrm{m}$ HEPA filter. The sensitive real-time RT-PCR analytical method should be used to evaluate other types of bioaerosol contamination in healthcare settings to monitor the indoor air quality and protect the public and healthcare personnel in hospitals.

\section{ACKNOWLEDGMENTS}

We thank Yu-Hwa Chang, Chung-Guei Huang, Hung-Chin Wang, and YaLing Huang for their assistance during this investigation.

This study was supported by grant CMRPD32020S from the Chang Gung Memorial Hospital of Taiwan.

From the Departments of Pulmonary and Critical Care (Y.-H.T., Y.-K.W.) and Clinical Pathology (K.-C.T.), Chang Gung Memorial Hospital, and Department of Respiratory Care, College of Medicine, Chang Gung University (G.-H.W.), Taiwan, Republic of China.

Address reprint requests to Gwo-Hwa Wan, $\mathrm{PhD}$, Department of Respiratory Care, College of Medicine, Chang Gung University, 259, Wen-Hwa 1st Road, Kwei-Shan, Tao-Yuan, Taiwan, Republic of China (ghwan@mail .cgu.edu.tw).

Received March 8, 2005; accepted October 18, 2005; electronically published April 26, 2006.

(C) 2006 by The Society for Healthcare Epidemiology of America. All rights reserved. 0899-823X/2006/2705-0019\$15.00.

\section{REFERE N C E S}

1. Drosten C, Gunther S, Preiser W, et al. Identification of a novel coronavirus in patients with severe acute respiratory syndrome. $N$ Engl J Med 2003; 348:1967-1976.

2. World Health Organization (WHO). Summary of probable SARS cases with onset of illness from 1 November 2002 to 31 July 2003. Available at: http://www.who.int/csr/sars/country/table2004_04_21/en/.

3. Inouye S. SARS transmission: language and droplet production. Lancet 2003; 362:170.

4. Duguid JP. The size and duration of air carriage of respiratory droplets and droplet nuclei. J Hyg 1946; 44:471-479.

5. Ksiazek TG, Erdman D, Goldsmith CS, et al. A novel coronavirus associated with severe acute respiratory syndrome. $N$ Engl J Med 2003; 348:1953-1966. 
6. World Health Organization (WHO). First data on stability and resistance of SARS coronavirus complied by members of WHO laboratory network. Available at: http://www.who.int/csr/sars/survival_2003_05_04/en/index .html.

7. Koubek C, Loose C, Sottili C. Protecting yourself as SARS fears increase. Washington Post April 13, 2003.

8. Lau ITF, Yang X, Leung PC, et al. SARS in three categories of hospital workers, Hong Kong. Emerg Infect Dis 2004; 10:1399-1404.

9. Teleman MD, Boudville IC, Heng BH, Zhu D, Leo YS. Factors associated with transmission of severe acute respiratory syndrome among healthcare workers in Singapore. Epidemiol Infect 2004; 132:797-803.

10. Li Y, Huang X, Yu ITS, Wong TW, Qian H. Role of air distribution in SARS transmission during the largest nosocomial outbreak in Hong Kong. Indoor Air 2004; 15:83-95.

11. Sawyer MH, Chamberlin CJ, Wu YN, Aintablian N, Wallace MR. De- tection of varicella-zoster DNA in air samples from hospital rooms. $J$ Infect Dis 1994; 169:91-94.

12. McCluskey R, Sandin R, Greene J. Detection of airborne Cytomegalovirus in hospital rooms of immunocompromised patients. J Virol Methods $1996 ; 56: 115-118$

13. Myatt TA, Johnston SL, Rudnick S, Milton DK. Airborne rhinovirus detection and effect of ultraviolet irradiation on detection by a seminested RT-PCR assay. BioMed Central Public Health 2003; 3:5.

14. Wan GH, Tsai YH, Wu YK, Tsao KC. A large-volume nebulizer would not be an infectious source for severe acute respiratory syndrome (SARS). Infect Control Hosp Epidemiol 2004; 25:1113-1115.

15. Taiwan's Center for Disease Control and Prevention. Standard Operation Procedures for Real-time RT-PCR in SARS-Related Coronavirus Identification. Taipei, Taiwan: Taiwan's Center for Disease Control and Prevention; 2003. Document No. CDC-LAB-MSOP-073. 